Sundman, V. \& AF Buörksten, K. (1958). J. gen. Microbiol. 19, 491-496

\title{
The Globular Involution Forms of the Bifid Bacteria
}

\author{
BY VERONICA SUNDMAN AND K. AF BJÖRKSTEN \\ Department of Microbiology, University of Helsingfors, Finland
}

SUMMARY: The globular swellings known to appear occasionally in cultures of the bifid bacteria have been shown to occur in all known types of Lactobacillus bifidus. The swellings developed on a substrate which permitted abundant growth. The development of the globular involution forms was prevented by the addition of tryptic digest of cow's milk to the substrate. The similarity between the globular forms of $\boldsymbol{L}$. bifidus and protoplasts is mentioned. The globular forms are considered to be organisms with incomplete cell walls which develop on a substrate adequate for growth but not for normal cell wall synthesis.

There are in the literature on the bifid bacteria (Lactobacillus bifidus) repeated notes on the occurrence of globular involution forms. Tissier (1900) stated that the whole organism can swell and give a bladder-like appearance as a response to acidity, extreme temperatures or inadequate nitrogen sources in the substrate. Orla-Jensen (1943) described his Bacterium bifidum strain no. 9 as extremely irregular with strongly clavate swellings. He assumed a relationship between morphology and physiological properties, and proposed as a possibility that the bladder-forming culture might represent a separate species. Negroni \& Fischer (1944) published a micrograph of these involution forms of $L$. bifidus without more detailed descriptions of the conditions in which they occurred. In Negroni \& Fischer (republished by Frank \& Skinner, 1954) a developing involution globe is seen at no. 10 in the camera lucida drawing. Hayward, Hale \& Bisset (1955), in a morphological study on L. bifidus, noted swollen and irregular organisms in some strains, and found a correlation between the abnormal morphology and sensitivity to oxygen. Olsen (1949) made an experiment to show whether the 'clubs' were a kind of resistant form, but could not find any increased heat resistance in cultures with many clubshaped organisms as compared with normal cultures.

Because of the pleomorphic character of the bifid bacteria, it may be difficult to decide whether a morphological feature is an involution form developed as a response to unfavourable surroundings, or belongs to the normal picture of the culture. The globular swellings dealt with in this paper are, with some experience, easily distinguished from the normally-occurring organisms with swollen ends. In its extreme form the involution bladder assumes a circular shape of $4 \mu$ diameter, with a structure like a cross on its surface. The bladders are not easy to detect in ordinary stained smears, but are clearly seen in water mounts in the phase contrast microscope (Pl. 1, fig. 1). Compared with the specific amphora-like organisms seen in $\mathrm{Pl}$. 1, fig. 2, and the swollen, bone-like organisms in $\mathrm{Pl}$. 1, fig. 3, the globular involution bladders are more circular in shape and mostly larger than the normal cells. 


\section{ORGANISMS AND MEDIA}

The strains studied were the same as in some other investigations (Gyllenberg \& Carlberg, 1958; Sundman, af Björksten \& Gyllenberg, to be published) and included thirteen isolates of infant origin and Lactobacillus bifidus var. pennsylvanicus ATCC 11863. The strains are listed in Table 1, and grouped on the basis of nutritional demands according to Gyllenberg \& Carlberg (1958) and in conformity with the classification of Dehnert (1957) which is based on fermentative, morphological and serological features.

Table 1. Grouping of the strains of Lactobacillus bifidus investigated

\begin{tabular}{lcc}
\multicolumn{1}{c}{ Strains studied } & $\begin{array}{c}\text { Nutritional type } \\
\text { (Gyllenberg) }\end{array}$ & $\begin{array}{c}\text { Group } \\
\text { (Dehnert) }\end{array}$ \\
$\mathbf{K}_{17}, \mathbf{M}_{1}, \mathbf{D}_{1}$ & A & IV \\
$\mathbf{A}_{1}, \mathbf{A}_{2}, \mathbf{A}_{4}, \mathbf{A}_{6}, \mathbf{E}_{15}$ & B & V \\
$\mathbf{B}_{18}, \mathbf{C}_{8}, \mathbf{C}_{25}$ & B & III \\
$\mathbf{B}_{4}, \mathbf{B}_{11}, \mathbf{1 1 8 6 3}$ & C & I-II
\end{tabular}

The stock cultures were kept in tomato agar stabs, incubated in a $\mathrm{CO}_{2}$ atmosphere at $37^{\circ}$ for 1-3 days and stored in the refrigerator for 7-14 days between the transfers. The tomato agar was a modification of the medium used by Petuely \& Lynau (1954).

Table 2. Composition of media

\begin{tabular}{|c|c|c|}
\hline & Tomato agar & G agar \\
\hline Sodium acetate & $1 \mathrm{~g}$. & - \\
\hline Ascorbic acid & - & $1 \mathrm{~g}$. \\
\hline Dibasic potassium phosphate & $0.5 \mathrm{~g}$. & $0.25 \mathrm{~g}$. \\
\hline Ammonium sulphate & $0 \cdot 4 \mathrm{~g}$. & - \\
\hline Casamino acids Difeo & - & $0.5 \mathrm{~g}$. \\
\hline Lactose & $3 \cdot 5 \mathrm{~g}$. & $3 \cdot 5 \mathrm{~g}$. \\
\hline Cystein hydrochloride & $0 \cdot 04 \mathrm{~g}$ & $0.04 \mathrm{~g}$. \\
\hline Ca pantothenate & $50 \mu \mathrm{g}$ & $50 \mu \mathrm{g}$. \\
\hline Biotin & $0.5 \mu \mathrm{g}$ & $0.5 \mu \mathrm{g}$. \\
\hline Salts B* & $0.5 \mathrm{ml}$ & $0.5 \mathrm{ml}$. \\
\hline Tween 80 & $0.5 \mathrm{ml}$ & $0.5 \mathrm{ml}$ \\
\hline Tomato agar Difco & $1 \mathrm{~g}$. & - \\
\hline Yeast extract Difco & - & $0.1 \mathrm{~g}$. \\
\hline Tryptic digest of cow's milk $\dagger$ & 一 & $5 \mathrm{ml}$. \\
\hline Human milk (skimmed) & - & $2 \mathrm{ml}$. \\
\hline Agar & $1.5 \mathrm{~g}$ & $1.5 \mathrm{~g}$. \\
\hline Distilled water & $100 \mathrm{ml}$ & $100 \mathrm{ml}$. \\
\hline pH value & $6 \cdot 6$ & $6 \cdot 6$ \\
\hline
\end{tabular}

* $\mathrm{MgSO}_{4} \cdot 7 \mathrm{H}_{2} \mathrm{O}, 10 \mathrm{~g}$.; $\mathrm{FeSO}_{4} \cdot 7 \mathrm{H}_{2} \mathrm{O}, 0.5 \mathrm{~g}$; $\mathrm{MnSO}_{4} . \mathrm{H}_{2} \mathrm{O}, 0.35 \mathrm{~g}$; $\mathrm{NaCl}, 0.5 \mathrm{~g}$. ; distilled water, $250 \mathrm{ml}$.

$\dagger 100 \mathrm{ml}$. sterilized skimmed milk and $50 \mathrm{mg}$. trypsin (Gurr) incubated at $37^{\circ}$ for $24 \mathrm{hr}$.

For morphological examination the medium of György (1953) supplemented with tryptic digest of cow's milk, human milk and agar was chosen. This medium is referred to below as $\mathbf{G}$ agar. The composition of media is given in Table 2. 


\section{RESULTS}

All the strains studied grew well on both media in a $\mathrm{CO}_{2}$ atmosphere. It was, however, noticed repeatedly that stab cultures in tomato agar, after vigorous growth during incubation, occasionally diminished their viability or lost it completely in a week in the refrigerator. In such cases the cultures could be restored by frequent transfers on $G$ agar.

When the morphology of the bifid strains was continuously studied on G agar plates, it became evident that during the first $15 \mathrm{hr}$. the cultures belonging to the nutritional type $\mathbf{B}$ and Dehnert's group V (see Table 1) contained numerous globular swellings. Such a young culture is seen in Fig. 1 . After incubation for one day the organisms assumed a more normal appearance and the globular swellings disappeared completely (Pl. 2, fig. 9). It was therefore assumed that the globular form either represented some early stage in the life cycle of the bifid bacteria or developed in the tomato agar stabs used as inoculum in the experiments. A closer examination of the stab cultures with the phase contrast microscope justified the latter alternative. All the strains studied produced globular swellings in the tomato agar. The globules were most numerous in the strains belonging to Dehnert's groups IV and V (see Table 1). The strains listed in the Table as type B, group III, as regards the number and size of the globules, had a position between the former strains and the strains of pennsylvanicus type (type C according to Gyllenberg; group I according to Dehnert) which showed more occasional and smaller globules.

The globular bladders could not be correlated with any growth phase of the cultures. They occurred on the tomato agar at every age of the culture, on plates as well as in stabs. On $\mathbf{G}$ agar no globules developed. The globular swellings on young $\mathbf{G}$ agar plates could all be attributed to the inoculum.

The micrographs in Pl. 1, figs. 4-7, represent the globule-containing growth on tomato agar of the different groups of strains as listed in Table 1. Each micrograph is representative for all the strains in the group since no morphological differences of significance could be detected within the groups (Sundman et al. to be published). The corresponding pictures of normal growth on $\mathbf{G}$ agar are seen in Pl. 2, figs. 8-11.

When the two media are compared, it seems obvious that the tomato agar, although permitting abundant growth, is deficient in some respect. Neither of the three components of the tomato agar which were not included in the $\mathbf{G}$ agar ( $\mathrm{Na}$ acetate, $\left(\mathrm{NH}_{4}\right)_{2} \mathrm{SO}_{4}$, Difco tomato agar) induced globular swellings when added to the $\mathbf{G}$ agar. When, conversely, the $\mathbf{G}$ agar components (Difco casamino acids, yeast extract, tryptic digest of cow's milk and human milk) were added separately to the tomato agar in the same concentrations as they occur in $\mathrm{G}$ agar and one of the most pronounced globule-forming strains $\left(\mathbf{A}_{4}\right)$ was grown on these substrates, it turned out that $5 \%(\mathrm{v} / \mathrm{v})$ tryptic digest of cow's milk completely suppressed the globule formation in the tomato agar. The other components added had no influence on the development of the globular swellings. Additional experiments, where the tomato agar was supplemented with smaller amounts $(3 \%, v / v$, and $1 \%, v / v)$ of the tryptic digest and with 
various quantities of untreated milk, respectively, showed that the untreated milk had no effect, nor had the addition of $1 \%(\mathrm{v} / \mathrm{v})$ tryptic digest; $3 \%(\mathrm{v} / \mathrm{v})$ tryptic digest was enough to suppress the globule formation to some degree, but the organisms still showed a tendency to swell.

\section{DISCUSSION}

During these experiments the strains showed no variation in their ability to grow on artificial media. The rate of growth was increased by frequent transfers, but no tendency to more aerobic growth was noticed. The globule formation was the same immediately upon isolation and after the strains had been kept for several months in the laboratory. Thus the observation by Hayward et al. (1955) that the swollen forms disappeared after prolonged artificial culture was not confirmed. Probably these authors worked with mixed cultures, the adaptation to aerobic growth suggests the presence of corynebacteria (cf. Gyllenberg, 1958).

The bladder-forming culture of Lactobacillus bifidus described by OrlaJensen (1943) was an arabinose-fermenting strain. Orla-Jensen suggested that the strain might represent a separate species, with the peculiar globular cell morphology and the ability to ferment pentoses as characteristics separating it from other bifid bacteria. Orla-Jensen's observation was confirmed in the present work in so far as the most pronounced bladder formers were all found to ferment pentoses, either xylose only (Dehnert's group IV) or arabinose and xylose (Dehnert's group V). As, however, the globular swellings are to be found in all the strains studied, they cannot be used as a differentiating characteristic in a future separation of $L$. bifidus into different species or subtypes. On the contrary, the ability to form involution bladders on the media used in the present study may serve as a more general characteristic of all L. bifidus types, especially as the examination of a number of related organisms (Sundman $e t$ al. to be published) did not reveal the peculiar globular swellings in others except $\boldsymbol{L}$. bifidus.

All types of bifid bacteria, independently of their basic growth requirements, are stimulated by the tryptic digest (personal communication from Dr H. Gyllenberg). It may be assumed that some peptide component in the cow's milk digest is required for normal growth. The morphological description of the Lactobacillus bifidus types by Dehnert (1957) does not contain any report on involution forms. The proteose peptone of the medium used, otherwise resembling our tomato agar, is assumed to have provided the peptide component necessary to prevent the development of involution bladders.

The bladder-forming tomato agar is not known to contain any growthsuppressing substances. The globular forms are therefore considered as the response of Lactobacillus bifidus to a nutritionally deficient environment. Lark (1958) reported the development of similar globular forms, induced by penicillin in a strain of Alcaligenes fecalis. The effect of penicillin lies in the blockage of the formation of new cell wall material (Park \& Strominger, 1957). Whereas the lysozyme-induced protoplasts of Bacillus megaterium are formed as a result 
of the attack of lysozyme on the Gram-positive cell wall (Weibull, 1953), the protoplast-like globules in $A$. fecalis are probably the consequence of the penicillin-blocked cell wall synthesis. In the case of the bifid bacteria, the synthesis of a normal cell wall seems to be more exacting than the other growth of the organism, and the protoplast-like bladders may appear as a result of a deficiency of the substrate. The known tendency of $L$. bifidus to show morphological variations when grown in vitro, being most regularly rod-shaped in the natural habitat, may point towards an exacting cell wall synthesis. The pleomorphic character of the bifid bacteria makes an exact description of their morphology rather difficult. Our observations indicate that special attention must be paid to the composition of the medium on which morphological observations for species characterization of the bifid bacteria are made.

\section{REFERENCES}

Dehnert, J. (1957). Untersuchung über die Gram-positive Stuhlflora des Brustmilchkindes. Zbl. Bakt. (1. Orig.), $169,66$.

Frank, H. A. \& Skinner, C. E. (1954). The relationship between Actinomyces bovis and Lactobacillus bifidus. Mycologia, 46, 728.

GyLlenberg, H. (1958). Specific contaminants in cultures of Lactobacillus bifidus. Acta path. microbiol. scand. (in the Press).

Gyllenserg, H. \& Carlberg, G. (1958). The nutritional characteristies of the Bifid Bacteria (Lactobacillus bifidus) of infants. Acta path. microbiol. scand. (in the Press).

György, P. (1953). A hitherto unrecognized biochemical difference between human milk and cow's milk. Pediatrics, 11, 98.

Hayward, A. C., Hale, C. M. F. \& Bisset, K. A. (1955). The morphology and relationships of 'Lactobacillus' bifidus. J. gen. Microbiol. 13, 292.

LARK, K. G. (1958). Abnormal growth induced by penicillin in a strain of Alcaligenes fecalis. Canad. J. Microbiol. 4, 165.

Negroni, P. \& Fischer, I. (1944). Estudio sobre el Lactobacillus bifidus (Tissier) Kulp y Rettger. Rev. inst. bacteriol. Carlos G. Malbrán, 12, 276.

OLSEN, E. (1949). Studies on the Intestinal Flora of Infants. Copenhagen: Ejnar Munksgaard.

Orla-Jensen, S. (1943). The Lactic Acid Bacteria. Ergänzungsband, Copenhagen: Ejnar Munksgaard.

Park, J. T. \& Strominger, J. L. (1957). The mode of action of penicillin. Science, 125, 99.

Petuely, F. \& Lynau, V. (1954). Ein einfacher Optimalnährboden für den Lactobacillus bifidus. Biochem. Z. 326, 62.

Tissier, H. (1900). Recherches sur la flore intestinale normale et patologique du nourrison. Thèse. Université de Paris. (Quoted by Olsen (1949), p. 83.)

Weibull, C. (1953). The isolation of protoplasts from Bacillus megaterium by controlled treatment with lysozyme. J. Bact. 66, 688 . 


\section{EXPLANATION OF PLATES}

All photographs are of water-mounted smears of Lactobacillus bifidus strains grown at $37^{\circ}$. The phase contrast equipment of the Leitz Dialux microscope was used. Magnification, $\times 2500$.

\section{Plate 1}

Fig. 1. Involution bladders. Strain $A_{6}$. Young surface culture (6 hr.) on G agar.

Fig. 2. Amphora-like organisms. Strain $B_{4}$. Surface culture (2 days) on $G$ agar.

Fig. 3. Swollen, bone-like organisms. Strain $M_{1}$. Stab culture (3 days) in tomato agar.

Figs. 4-7. Tomato agar stab cultures (2 days) of the four different groups of strains as listed in Table 1 in the text. Fig. 4: strain $K_{17} ;$ fig. 5: strain $A_{4} ;$ fig. 6: strain $B_{18}$, fig. 7 : strain $\mathbf{B}_{11}$.

\section{Prate 2}

Surface cultures on $\mathrm{G}$ agar at $37^{\circ}$ of the four different groups of strains as listed in Table 1 in the text.

Fig. 8. Strain $D_{1}$ (3 days).

Fig. 9. Strain $A_{8}$ (1 day).

Fig. 10. Strain $C_{8}$ (4 days).

Fig. 11. Strain $B_{11}$ (1 day).

(Received 27 May 1958) 
Journal of General Microbiology, Vol. 19, No. 3

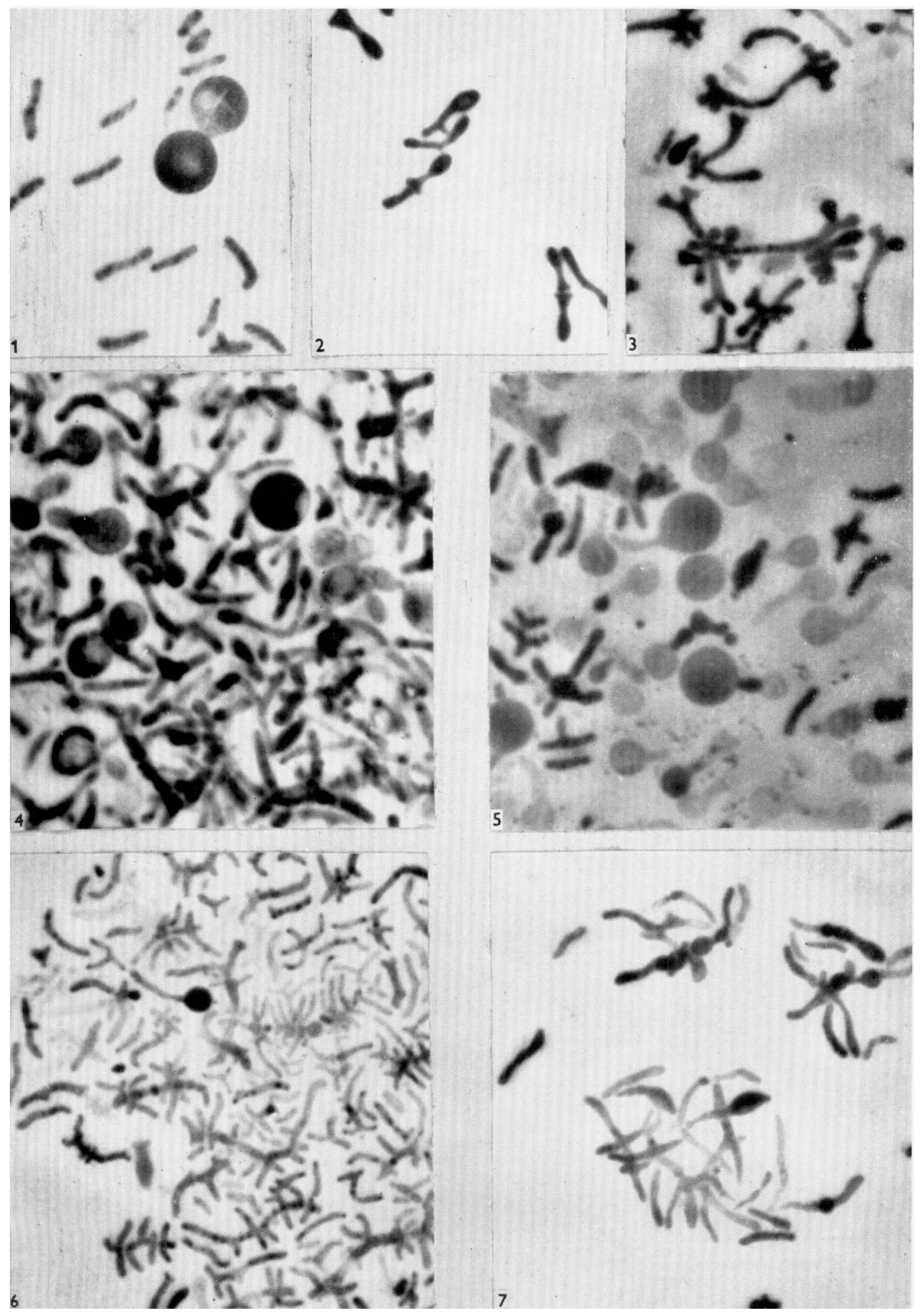

V. Sundman \& K. aF BJörksten-Globular forms of L. blFidus. Plate 1 
Journal of General Microbiology, Vol. 19, No. 3

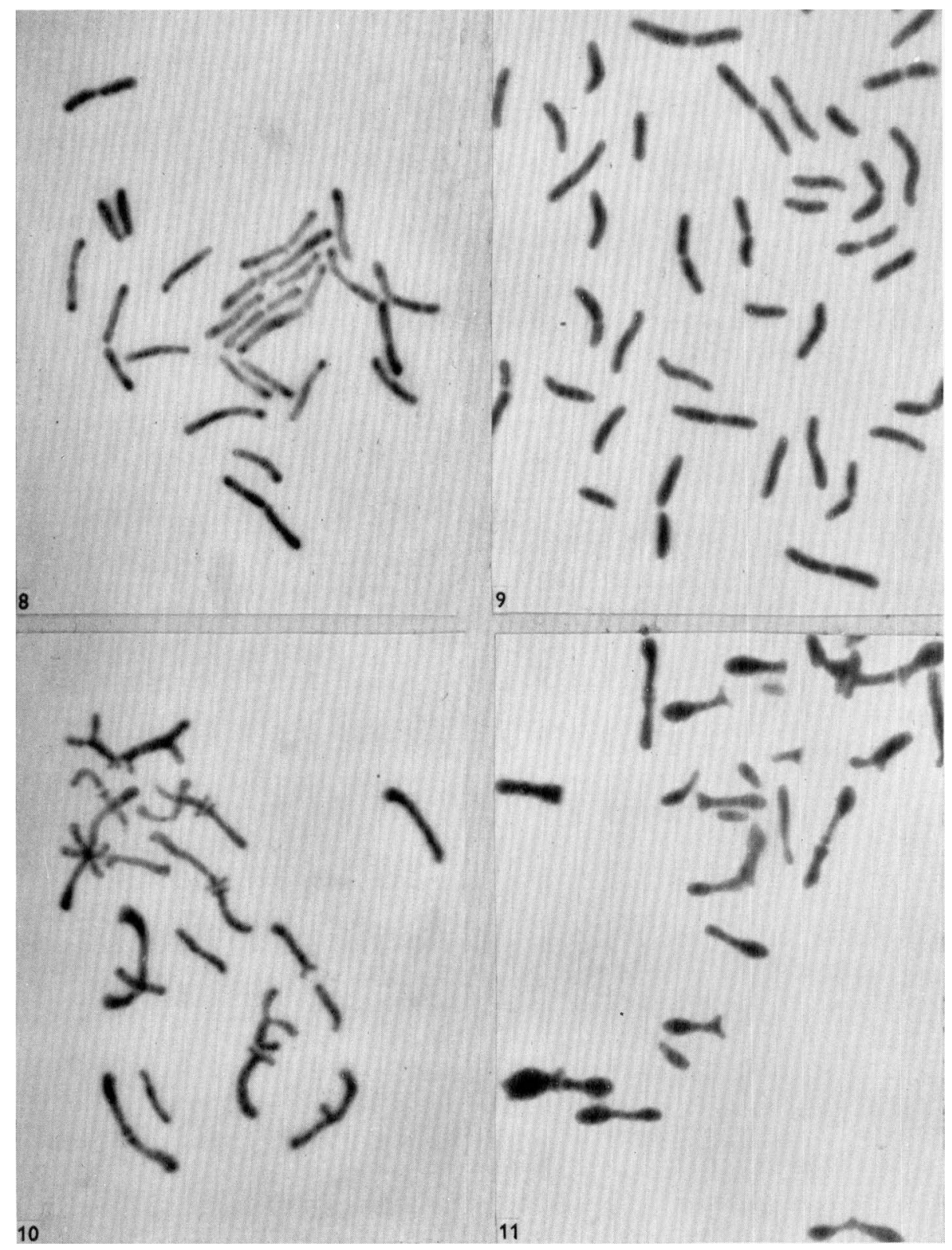

V. Sundman \& K. af Buörksten-Globular forms of L. Bifidus. Plate 2 